\title{
PENERAPAN METODE SIMPLE ADDITIVE WEIGHTING SEBAGAI ALTERNATIF UNTUK MENUNJANG KEPUTUSAN PEMILIHAN GURU TERBAIK PADA SMK PUSTEK SERPONG
}

\author{
Desty Shara Suhandi ${ }^{1)}$, Goenawan Brotosaputro ${ }^{2)}$ \\ ${ }^{1}$ Sistem Informasi, Fakultas Teknologi Informasi, Universitas Budi Luhur \\ ${ }^{1,2} \mathrm{JI}$. Raya Ciledug, Petukangan Utara, Kebayoran Lama, Jakarta Selatan 12260 \\ E-mail : destysharasuhandi37@gmail.com ${ }^{1)}$, goenawan.brotosaputro@budiluhur.ac.id" ${ }^{2}$
}

\begin{abstract}
Abstrak
Semakin berkembangnya teknologi informasi di era globalisasi saat ini, menjadikan teknologi sebagai kebutuhan sehari-hari bagi semua orang. Khususnya di dunia pendidikan suatu pendidikan tidak akan berkembang/berjalan tanpa adanya beberapa faktor pendukung, salah satu faktor pendukung tersebut adalah sistem informasi. Berdasarkan perkembangan informasi yang berkembang di dunia pendidikan, SMK Pustek Serpong sangat membutuhkan sistem informasi yang akurat dan mempermudah pihak sekolah dalam menentukan pemilihan guru terbaik. Masalah yang ada dalam pemilihan guru terbaik adalah kesulitan dalam proses pegumpulan data dan hasil keputusan, belum adanya metode yang tepat dalam penentuan penilain guru terbaik, belum adanya sistem penunjang keputusan untuk pemilihan guru terbaik, sehingga pengambilan keputusan kurang efektif. Untuk mengatasi permasalahan yang ada di SMK Pustek Serpong, dibutuhkan Sistem Penunjang Keputusan untuk membantu dalam pengambilan hasil keputusan, dengan menggunakan metode Simple Additive Weighting (SAW), serta membuatkan database MySQL untuk menyimpan semua data. Maka dari itu dibuatkanlah Sistem Penunjang keputusan untuk mempermudah Bagian Kurikulum dalam melakukan penilaian guru terbaik, dengan adanya metode SAW dapat memudahkan penilaian yang sudah terbobot dari setiap alternatif yang ada, dibuatkan database agar mempermudah dalam membuat data dan menyimpan datadata yang sudah dibuat agar tersimpan aman.
\end{abstract}

Kata kunci: SMK Pustek Serpong, Pemilihan Guru Terbaik, Simple Additive Weighting (SAW)

\section{PENDAHULUAN}

Teknologi dapat memberikan banyak kemudahan dalam melakukan aktivitas manusia seperti meningkatkan efisiensi dan efektivitas kerja. Kegiatan yang menggunakan teknologi informasi adalah sistem informasi di dunia pendidikan, perbankan, transaksi jual beli, dan lain-lain.

Didalam dunia pendidikan sistem informasi sangatlah penting untuk proses pengolahan dan mempercepat proses kerja. Pihak sekolah pun dituntut untuk mengembangkan operasional untuk meningkatkan pelayanan terhadap siswa, orang tua/ wali siswa dan masyarakat. Oleh karena itu pihak sekolah perlu melakukan perubahan dalam melaksanakan kegiatan operasional sekolah. Seperti salah satunya mengubah sistem manual ke sistem informasi. Perubahan tersebut nantinya akan dapat mempermudah dan mempersingkat pekerjaan. Salah satu sistem informasi yang dibutuhkan adalah sistem penunjang keputusan pemilihan guru terbaik.

Dengan perkembangan teknologi informasi di dunia pendidikan, SMK Pustek Serpong sangat membutuhkan sistem informasi yang akurat dan mempermudah pihak sekolah untuk membantu menentukan pemilihan guru terbaik. Hal ini diperlukan karena Bagian kurikulum kesulitan dalam proses pengumpulan data dan hasil keputusan penilaian kinerja guru, sehingga proses penilaian kinerja guru terbaik kurang maksimal dan memakan waktu yang lama untuk merekap data, kemudian belum adanya sistem penunjang keputusan untuk pemilihan guru terbaik pada SMK Pustek Serpong, sehingga pengambilan keputusan kurang efektif, dan belum adanya metode yang tepat dalam penentuan penilaian guru terbaik, sehingga penilaian masih menggunakan hitungan perkiraan.

Adapun Studi literatur dari beberapa penelitian sebelumnya yang berkaitan dengan penentuan pegawai terbaik, diantaranya menggunakan SAW. Diantaranya penelitian yang dilakukan oleh [1], mempunyai kriteria yaitu absensi, indeks prestasi individual, indeks prestasi siswa yang dibina, penilaian kuisioner, interaksi sosial, pendidikan terakhir. Dengan nilai hasil akhir terbesar 88.9 yang dimiliki oleh allternatif A10.

Berikut penelitian yang dilakukan oleh [2] yang mempunyai kriteria Kinerja Guru, Absensi Guru, Wawasan Guru, Tanggung Jawab Guru, Cara Mengajar Guru. Dengan nilai hasil akhir terbesar 0,95 dengan nama guru Elie Sundari, S.Pd.

Kemudian penelitian yang dilakukan oleh [3] yang mempunyai kriteria Kedisiplinan, Prakarsa, Prestasi, Tanggung Jawab, Menjaga Nama Baik. 
Dengan nilai hasil akhir terbesar 0,96 yang dimiliki oleh alternatif V4.

\section{METODE PENELITIAN}

\subsection{Metode Pengumpulan Data}

Dalam melakukan penelitian ini penulis melakukan pengumpulan data dengan cara pengamatan, wawancara, studi kasus, dan analisa dokumen.

\section{a. Pengamatan (Observation)}

Dalam kegiatan ini dilakukan pengumpulan data dengan cara mengamati secara langsung dengan hal-hal yang berhubungan dengan Sistem Penunjang Keputusan pemilihan guru terbaik dan sebagai masukan dalam penelitian ini.

\section{b. Wawancara (Interview)}

Wawancara ini dilakukan dengan Bidang Kurikulum yang melakukan pemilihan guru terbaik guna mendapatkan informasi tentang pemilihan guru terbaik. Dari hasil wawancara tersebut penulis mendapatkan dokumen-dokumen yang digunakan untuk mengembangkan sistem penunjang keputusan guru terbaik.

\section{c. Studi Pustaka}

Kegiatan ini dilakukan dengan cara membaca referensi dari beberapa jurnal yang berkaitan dengan teori pemilihan guru terbaik, teori Sistem Penunjang Keputusan, teori Simple Additive Weighting, dan teori yang berkaitan dengan pembuatan Sistem Penunjang Keputusan.

d. Analisa Dokumen

Analisa dokumen dilakukan untuk menganalisa dokumen berjalan untuk mendapatkan informasi yang sesuai dengan sistem yang akan dibuat.

e. Hasil dan Pembahasan

Masalah pada penelitian di SMK Pustek Serpong adalah sering mengalami kesulitan saat melakukan pemilihan guru terbaik diantaranya faktor proses, dan metode, sistem. Faktor proses mengakibatkan proses penilaian kinerja guru kurang maksimal dan memakan waktu lama saat merekap data. Faktor sistem belum adanya sistem penunjang keputusan, sehingga pengambilan keputusan kurang efektif. Sedangkan faktor metode mengakibatkan hasil penilaian masih menggunakan hitungan perkiraan. Semua permasalahan yang disebutkan dapat dilihat pada Gambar 1 Fishbone

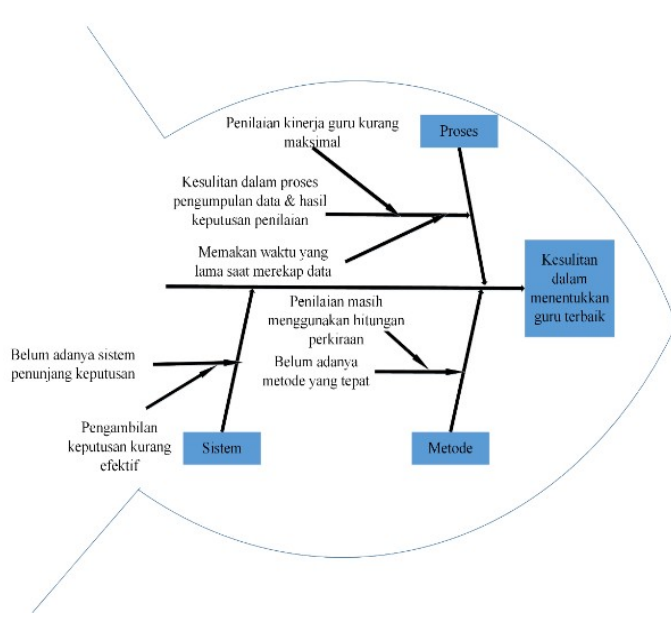

Gambar 1. Fishbone

\subsection{Proses Bisnis}

Proses penilian kinerja guru terbaik di SMK Pustek Serpong dilakukan setiap tahun. Penilaian dilakukan berdasarkan kinerja guru. Pertama bagian bidang kurikum akan mengisi daftar penilaian guru, kemudian melakukan penilaian kinerja guru terbaik, setelah itu bagian kurikulum merekap data penilaian masing-masing guru, kemudian Bagian Kurikulum akan memutuskan nama-nama guru terbaik, kemudian Bidang Kurikulum akan menyerahkan nama-nama guru terbaik kepada Kepala Sekolah. Kepala Sekolah menerima nama-nama guru terbaik oleh Bagian Kurikulum, lalu Kepala Sekolah akan mengadakan rapat pertemuan, kemudian Kepala Sekolah akan mengumumkan siapa yang menjadi guru terbaik pada periode tahun ajaran tersebut. Seperti terlihat pada Gambar 2 Activity Diagram Berjalan.

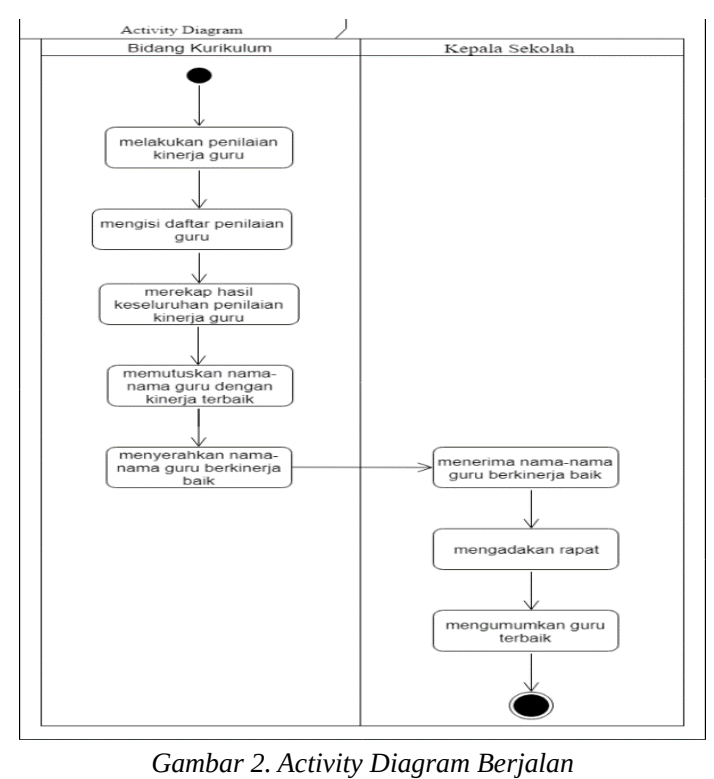




\subsection{Metode Simple Additive Weighting (SAW)}

Konsep dasar metode SAW adalah mencari penjumlahan terbobot dari rating kinerja pada setiap alternative dari semua atribut. Metode ini merupakan metode yang paling terkenal dan paling banyak digunakan dalam menghadapi situasi Multiple Attribute Decision Making (MADM). MADM itu sendiri merupakan suatu metode yang digunakan untuk mencari alternatif optimal dari sejumlah alternative dengan criteria tertentu. Metode SAW ini mengharuskan pembuat keputusan menentukan bobot bagi setiap atribut. Skor total untuk alternative diperoleh dengan menjumlahkan seluruh hasil perkalian antara rating (yang dapat dibandingkan lintas atribut) dan bobot tiap atribut. Rating pada setiap atribut harus bebas dari dimensi dalam arti telah melewati proses normalisasi matriks sebelumnya.

$$
r_{i j}=\left\{\begin{array}{l}
\frac{x_{i j}}{M_{i j} x_{i j}} \text { jika } j \text { adalah attribut keuntungan (benefit) } \\
\frac{M_{i n} x_{i j}}{x_{i j}} \\
\text { jika } j \text { adalah attribut biaya (cost) }
\end{array}\right.
$$

Dimana :

Rij =Rating kinerja ternormalisasi

Maxij =Nilai maksimum dari setiap baris dan kolom

Minij =Nilai minimum dari setiap baris dan

kolom

$\mathrm{Xij}=$ Baris dan kolom dari matriks

Dengan Rij adalah rating kinerja ternormalisasi dari alternatif Ai pada atribut $\mathrm{Cj} ; \mathrm{i}=1,2, \ldots \mathrm{m}$ dan $\mathrm{j}$ $=1,2, \ldots$, n.

Langkah penyelesaian menggunakan metode SAW :

a. Menentukan kriteria yang akan dijadikan acuan dalam pengambilan keputusan.

b. Menentukan bobot nilai dari masing-masing kriteria yang sudah didapatkan sebelumnya. Seperti pada Tabel 1

Tabel 1. Tabel Kriteria

\begin{tabular}{ll}
\hline Nama Kriteria & Bobot \\
\hline KKT1 & $20 \%$ \\
KKT2 & $30 \%$ \\
KKT3 & $20 \%$ \\
KKT4 & $30 \%$ \\
Total & $100 \%$ \\
\hline
\end{tabular}

Kelebihan metode SAW dengan metode lainnya yaitu penilaian yang lebih tepat karena berdasarkan nilai kriteria dan bobot yang sudah ada, SAW juga dapat menyeleksi alternative terbaik dari beberapa alternatif yang ada karena proses perankingan sesudah memastikan nilai bobot atribut. [4]. Yang diperlukan dalam dalam pemilihan keputusan dengan menggunakan metode Simple Additive Weighting (SAW) adalah:

a) Identifikasi Tujuan

Tujuan dari penelitian ini untuk pemilihan guru terbaik pada SMK Pustek Serpong, yang dinilai berdasarkan kriteria-kriteria yang sudah ada beserta bobot yang sudah ada dari masing-masing kriteria. Kemudian untuk melakukan perhitungan alternatif dengan masing-masing kriteria akan dilakukan menggunakan metode Simple Additive Weighting (SAW). Berikut adalah nama-nama kandidat guru yang terdapat pada Tabel 2 Nama Kandidat dan Kode Alternatif

Tabel 2. Nama Kandidat dan Kode Alternatif

\begin{tabular}{|c|c|}
\hline Kode Alternative & Nama Kandidat \\
\hline 082 & Anita Triyana, S.Kom \\
\hline 171 & Muhammad Arief, M.Kom \\
\hline 148 & Chodik Kriwanto, Ir. \\
\hline 132 & Euis Supianah, S.Pd. \\
\hline 087 & Desy Kusumasari, SE \\
\hline
\end{tabular}

b) Identifikasi Kriteria

Pada tabel dibawah ini merupakan kriteria yang dibutuhkan SMK Pustek Serpong untuk pengambilan keputusan penilaian kinerja guru terbaik. Berdasarkan bobot kriteria yang sudah ada. Total bobot, jumlahkan tidak boleh melebihi $100 \%$. Seperti pada Tabel 3 Ketentuan Kriteria dan Presentase Bobot Kriteria.

Tabel 3. Ketentuan Kriteria dan Presentase Bobot Kriteria

\begin{tabular}{|c|c|c|c|}
\hline $\begin{array}{c}\text { Kode } \\
\text { Kriteria }\end{array}$ & Nama Kriteria & Kategori & Bobot \\
\hline 1 & Pedagogik & Benefit & 0.2 \\
\hline 2 & Keperibadian & Benefit & 0.3 \\
\hline 3 & Sosial & Benefit & 0.2 \\
\hline 4 & Profesional & Benefit & 0.3 \\
\hline \multicolumn{3}{|c|}{ Total } & 1 \\
\hline
\end{tabular}

c) Matriks Normalisasi

Untuk mendapatkan matriks normalisasi, diperlukan nilai masing-masing alternatif yang dihasilkan dari jumlah nilai kriteria. Seperti pada Tabel 4 Nilai Rata-rata Per Sub Kriteria 
Tabel 4. Nilai Rata-rata Per Sub Kriteria

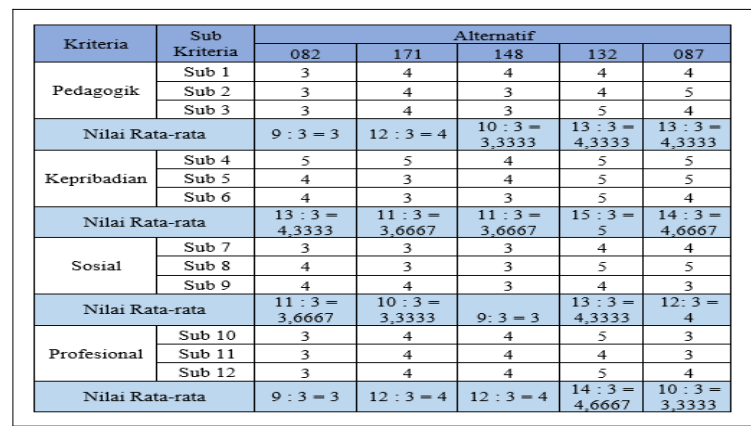

Tabel 5. Nilai Alternatif Perkriteria

\begin{tabular}{|c|c|c|c|c|}
\hline \multirow{2}{*}{ Alternatif } & \multicolumn{5}{|c|}{ Kriteria } \\
\cline { 2 - 5 } & Pedagogik & Kepribadian & Sosial & Profesional \\
\hline 082 & 3 & 4,3333 & 3,6667 & 3 \\
\hline 171 & 4 & 3,6667 & 3,3333 & 4 \\
\hline 148 & 3,3333 & 3,6667 & 3 & 4 \\
\hline 132 & 4,3333 & 5 & 4,3333 & 4,6667 \\
\hline 087 & 4,3333 & 4,6667 & 4 & 3,3333 \\
\hline
\end{tabular}

Kemudian melakukan normalisasi menjadi matriks $\mathrm{r}$ untuk hitung nilai kriteria-kriteria , menghitung dari kriteria keuntungan atau kriteria biaya dengan persamaan sebagai berikut:

1) Perhitungan Kriteria Pedagogik

$$
\begin{aligned}
& R_{11}=\frac{3}{4,3333}=0,6923 \\
& R_{21}=\frac{4}{4,3333}=0,9231 \\
& R_{31}=\frac{3,3333}{4,3333}=0,7692 \\
& R_{41}=\frac{4,3333}{4,3333}=1,0000 \\
& R_{51}=\frac{4,3333}{4,3333}=1,0000
\end{aligned}
$$

2) Perhitungan Kriteria Keperibadian

$$
\begin{aligned}
& R_{12=\frac{4,3333}{5}}=0,8667 \\
& R_{22}=\frac{3,6667}{5}=0,7333 \\
& R_{32}=\frac{3,6667}{5}=0,7333 \\
& R_{42}=\frac{5}{5}=1,0000 \\
& R_{52}=\frac{4,6667}{5}=0,9333
\end{aligned}
$$

3) Perhitungan Kriteria Sosial

$$
\begin{aligned}
& R_{13}=\frac{3,6667}{4,3333}=0,8462 \quad R_{23}=\frac{3,3333}{4,3333}=0,7692 \\
& R_{33}=\frac{3}{4,3333}=0,6923 \\
& R_{43}=\frac{4,3333}{4,3333}=1,0000 \\
& R_{53}=\frac{4}{4,3333}=0,9231
\end{aligned}
$$

4) Perhitungan Kriteria Profesional

$$
\begin{aligned}
& R_{14=\frac{3}{4,6667}}=0,6429 \\
& R_{24}=\frac{4}{4,6667}=0,8571 \\
& R_{34}=\frac{4}{4,6667}=0,8571 \\
& R_{44}=\frac{4,6667}{4,6667}=1,0000 \\
& R_{54=\frac{3,3333}{4,6667}}=0,7143
\end{aligned}
$$

\subsection{Hasil Nilai Normalisasi}

Dari hasil matriks normalisasi yang sudah didapatkan dari setiap kriteria yang sudah ada untuk dihitung agar mendapatkan nilai alternatif yang terbaik seperti pada Tabel 6 Hasil Nilai Normalisasi

Tabel 6. Hasil Nilai Normalisasi

\begin{tabular}{|c|c|c|c|c|}
\hline Alternatif & Pedagogik & Keperibadian & Sosial & Profesional \\
\hline $\mathbf{0 8 2}$ & 0,6923 & 0,8667 & 0,8462 & 0,6429 \\
\hline $\mathbf{1 7 1}$ & 0,9231 & 0,7333 & 0,7692 & 0,8571 \\
\hline $\mathbf{1 4 8}$ & 0,7692 & 0,7333 & 0,6923 & 0,8571 \\
\hline $\mathbf{1 3 2}$ & 1,0000 & 1,0000 & 1,0000 & 1,0000 \\
\hline $\mathbf{0 8 7}$ & 1,0000 & 0,9333 & 0,9231 & 0,7143 \\
\hline Bobot & $\mathbf{0 . 2}$ & $\mathbf{0 . 3}$ & $\mathbf{0 . 2}$ & $\mathbf{0 . 3}$ \\
\hline
\end{tabular}

1) 082

$=\{(0,6923 \times 0,2)+(0,8667 \times 0,3)+(0,8462 \times 0,2)+$ $(0,6429 \times 0,3)\}$

$=\{(0,1385+0,2600+0,1692+0,1929)\}$

$=0,7606$

2) 171

$=\{(0,9231 \times 0,2)+(0,7333 \times 0,3)+(0,7692 \times 0,2)+($

$0,8571 \times 0,3)$

$=\{(0,1846+0,2201+0,1538+$

$0,2571)\}$

$=0,8156$

3) 148

$=\{(0,7692 \times 0,2)+(0,7333 \times 0,3)+(0,6923 \times 0,2)+($

$0,8571 \times 0,3)\}$

$=\{(0,1538+0,2201+0,1385+0,2571)\}$

$=0,7695$

4) 132

$=\{(1,0000 \times 0,2)+(1,0000 \times 0,3)+(1,0000 \times 0,2)+($ $1,0000 \times 0,3)\}$

$=\{(0,2+0,3+0,2+0,3)\}$

$=1$

5) 087

$=\{(1,0000 \times 0,2)+(0,9333 \times 0,3)+(0,9231 \times 0,2)+($

$0,7143 \times 0,3)\}$

$=\{(0,2+0,2799+0,1847+0,2143)\}$

$=0,8789$ 


\section{HASIL DAN PEMBAHASAN}

\subsection{Hasil penelitian}

Setelah melakukan perhitungan dengan metode SAW maka diputuskan bahwa guru dengan kode 132 yang bernama (Euis Supianah, S.Pd) terpilih sebagai guru terbaik dengan memperoleh nilai tertinggi 1 . Tetapi semua keputusan tetap ditentukan oleh Kepala Sekolah SMK Pustek Serpong.

\subsection{Perancangan Sistem}

Terdapat tiga use case diagram yang terdiri dari master, transaksi, laporan, yang terdapat pada gambar 3,4,5. Pada gambar 3 terdiri dari entri guru, entri kriteria, entri subkriteria,entri periode. Pada gambar 4 terdiri dari entri nilai alternatif, perhitungan normalisasi, cetak guru terbaik, dan entri guru terbaik. Kemudian pada gambar 5 terdiri dari cetak laporan ranking, cetak laporan evaluasi, dan cetak guru terbaik.

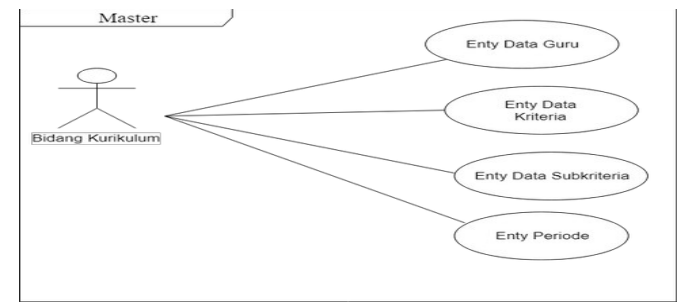

Gambar 3. Use case Master

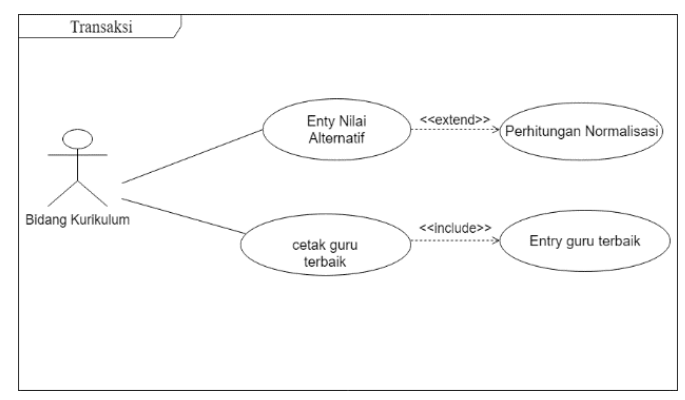

Gambar 4. Use case Transaksi

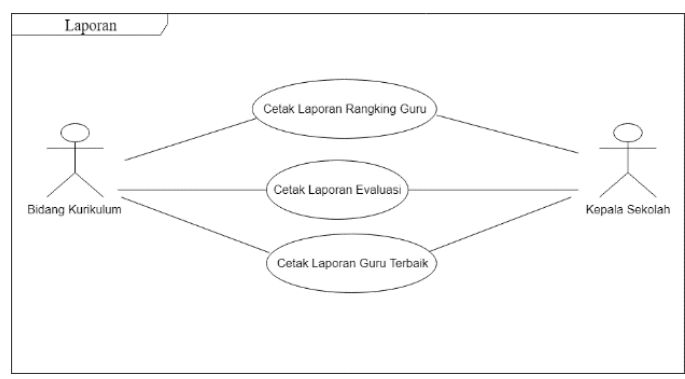

Gambar 5. Use case Laporan

\subsection{Rancangan Layar}

a. Menu utama

Sistem yang dijalankan, pertama akan keluar form menu utama. Terdapat tiga menu utama master, analisa, laporan, dimana masing-masing menu mempunyai submenu.

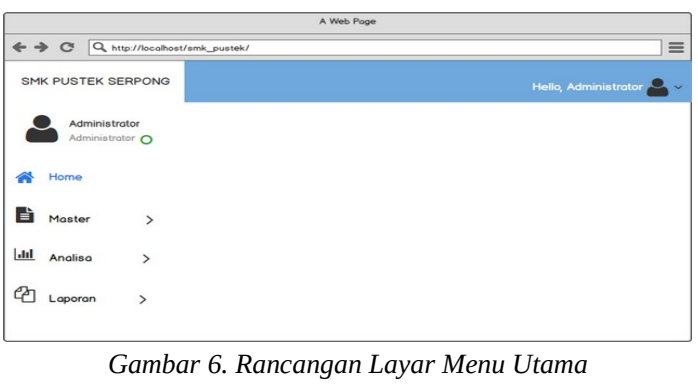

b. Entri Guru

form entry data guru untuk meng-entry data guru yang ada pada SMK Pustek Serpong. User bisa menambahkan data guru kemudian klik tombol simpan untuk menyimpan data. user dapat mengubah data yang sudah ada dengan cara klik edit lalu menyimpan data dengan klik tombol simpan. Klik tombol hapus untuk menghapus data guru yang ingin dihapus.
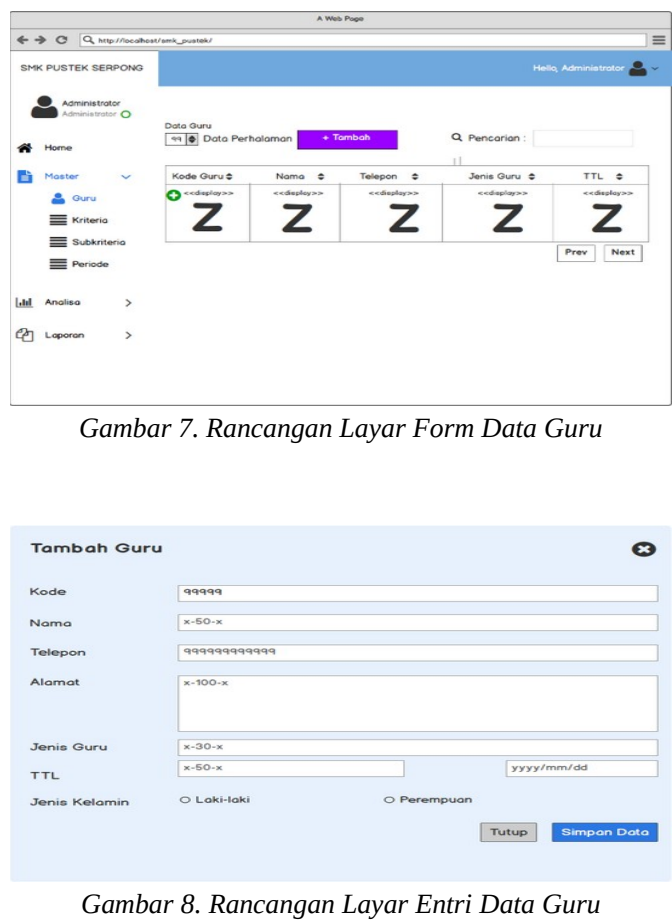

c. Entri Nilai Alternatif

untuk mengentri nilai alternatif user dapat memilih kandidat guru untuk dinilai , user dapat entri nilai dari masing- masing guru. 


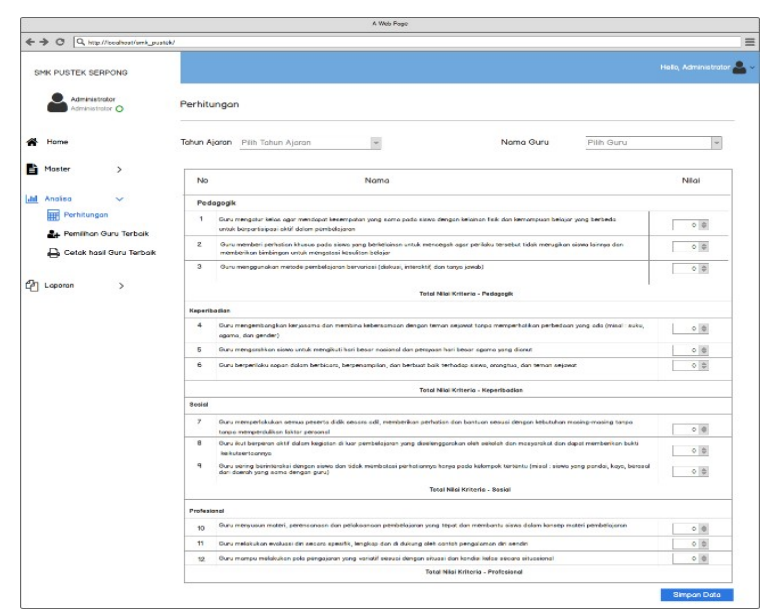

Gambar 9. Rancangan Layar Entri Nilai Alternatif

d. Rancangan Layar Nilai Normalisasi

Jika user ingin menormalisasi nilai tersebut maka user dapat mengklik tombol lanjut perhitungan Normalisasi untuk melakukan perhitungan.

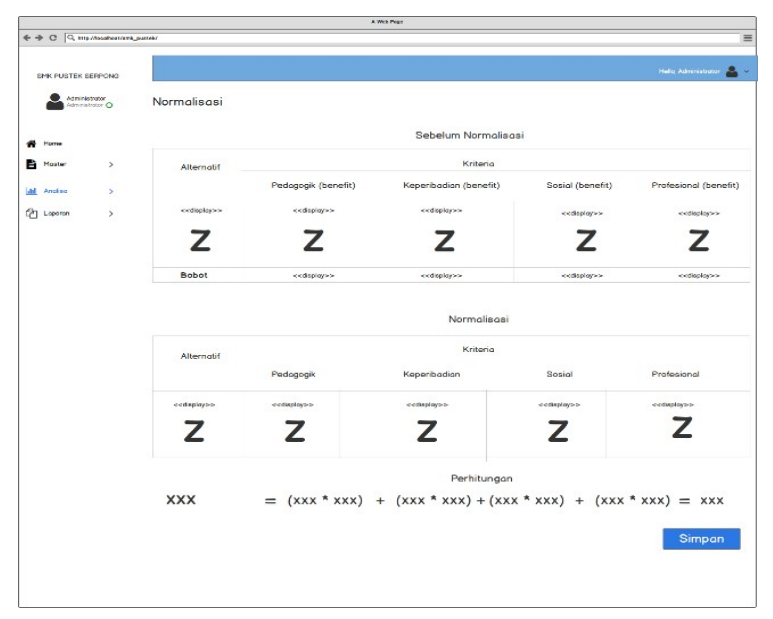

Gambar 10. Rancangan Layar Nilai Normalisasi

e. Rancangan Layar Cetak Hasi Guru Terbaik form cetak hasil guru terbaik.User dapat memilih tahun ajaran kemudian klik cari, muncul nama guru terbaik yang terpilih pada tahun ajaran tersebut.User bisa klik tombol print untuk mencetak hasil .

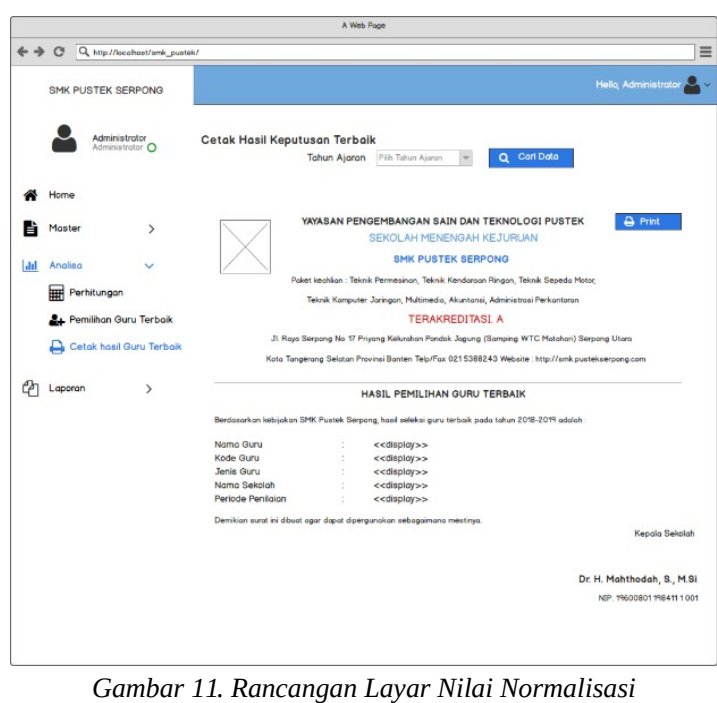

\section{KESIMPULAN}

Berdasarkan penelitian yang telah dilakukan pada SMK Pustek Serpong, maka dapat disimpulan sebagai berikut :

a. Dengan dibuatkan sistem penunjang keputusan ini, dapat membantu Bidang Kurikulum SMK Pustek Serpong dalam menentukan pemilihan guru terbaik, karena didalam sistem sudah dibuatkan menu analisa yang di dalamnya terdapat form perhitungan untuk menghitung nilai alternatif dan normalisasi, kemudian ada form pemilihan guru terbaik untuk memilih siapa yang menjadi guru terbaik, dan di menu cetak laporan terdapat form laporan ranking yang dapat menentukan ranking dari guru-guru yang terpilih menjadi guru terbaik.

b. Dengan metode SAW dapat memudahkan dalam proses perhitungan karena mencari penjumlahan terbobot dari rating kinerja pada setiap alternative dan semua atribut, sehingga dapat mempermudah Bidang Kurikulum dalam proses penilaian guru terbaik

c. Dibuatkannya database agar mempermudah Bidang Kurikulum dalam mengolah data dengan cepat dan menyimpan data-data yang sudah tersimpan agar aman.

\section{DAFTAR PUSTAKA}

[1] A. S. Putra, D. R. Aryanti, and I. Hartati, "Metode SAW (Simple Additive Weighting) sebagai Sistem Pendukung Keputusan Guru Berprestasi (Studi Kasus: SMK Global Surya),” Pros. Semin. Nas. Darmajaya, vol. 1, no. 1, pp. 85-97, 2018.

[2] Y. E. Chintyari and T. Priharin, "Implementasi Metode Simple Additive Weighting untuk pemilihan Guru beprestasi pada SMP Islam Pondok Duta,” $J$. 
Ilmu Pengetah. dan Teknol. Komput., vol. 3, no. 2, pp. 81-89, 2015.

[3] R. S. Hutasoit, A. P. Windarto, D. Hartama, and S. Solikhun, "Sistem Pendukung Keputusan Pemilihan Guru Terbaik Pada Smk Maria Goretti Pematangsiantar Menggunakan Metode Simple Additive Weighting (Saw),” Jurasik (Jurnal Ris. Sist. Inf. dan Tek. Inform., vol. 1, no. 1, p. 56, 2018.

[4] T. R. Adianto, Z. Arifin, D. M. Khairina, G. Mahakam, and G. Palm, "SISTEM PENDUKUNG KEPUTUSAN PEMILIHAN RUMAH TINGGAL DI PERUMAHAN MENGGUNAKAN METODE SIMPLE ADDITIVE WEIGHTING (SAW) (STUDI KASUS: KOTA SAMARINDA)," in Prosiding Seminar Ilmu Komputer dan Teknologi Informasi, 2017, vol. 2, no. 1, pp. 197-201. 